\title{
Perancangan Sistem Informasi Mutasi Siswa SMA pada Dinas Pendidikan Provinsi Jawa Barat
}

\author{
Meliyana Dwi Cahya ${ }^{1}$; Leonardi Paris Hasugian ${ }^{2}$ \\ ${ }^{1}$ Departemen Teknik dan Ilmu Komputer, Universitas Komputer Indonesia, Indonesia \\ ${ }^{2}$ Departemen Teknik dan Ilmu Komputer, Universitas Komputer Indonesia, Indonesia \\ 1'meliyanadwicahya79@gmail.com
}

\begin{abstract}
The West Java Provincial Office is a company engaged in education services, which has several parts, one of which is the High School Development (PSMA) field. PSMA itself has not used an information system in the registration process of student mutations, where problems faced by registrants want to request a mutation referral letter, referral letters are not always completed on time. registrars do not know the flow of procedures, and other constraints are on file storage that tends to accumulate. The purpose of the study is to notify the registrant that a referral letter has been completed, notify the registrant of the path - what paths must be done by the registrant and make it easier when searching the file for the registration mutation. The method used, namely using descriptive methods. which is aimed at gathering information about a problem. The results of this study are to notify the registrant that the referral letter has been completed or processed, notify the registrant of the path - what paths the registrant must do, and make it easier when searching the file for the registration mutation.
\end{abstract}

Keywords: Design, Information System, Mutation

\begin{abstract}
ABSTRAK
Dinas Provinsi Jawa Barat merupakan sebuah perusahaan yang bergerak dibidang pelayanan pendidikan, yang memiliki beberapa bagian salah satunya bidang Pembinaan Sekolah Menengah Atas (PSMA). PSMA sendiri belum menggunakan sebuah sistem informasi pada proses pendaftaran mutasi siswa, dimana masalah yang dihadapi pendaftar ingin meminta surat rujukan mutasi, surat rujukan tidak selalu selesai dengan tepat waktu. pendaftar tidak mengetahui alur prosedur, dan kendala lainnya ada pada penyimpanan berkas yang cenderung menumpuk. Tujuan dari penelitian tersebut adalah Untuk memberitahu pendaftar bahwa surat rujukan telah selesai dibuat, memberitahukan pendaftar alur - alur apa saja yang harus dilakukan oleh pendaftar dan mempermudah saat melalukan pencarian berkas pendaftar mutasi. Metode yang digunakan, yaitu menggunakan metode deskriptif. yaitu bertujuan untuk mengumpulkan informasi mengenai suatu masalah. Hasil dari penelitian ini adalah untuk memberitahu pendaftar bahwa surat rujukan telah selesai di buat atau di proses, memberitahukan pendaftar alur - alur apa saja yang harus dilakukan oleh pendaftar, dan mempermudah saat melalukan pencarian berkas pendaftar mutasi.
\end{abstract}

Kata kunci: Perancangan, Sistem Informasi, Mutasi 


\section{PENDAHULUAN}

Komputer merupakan salah satu hasil dari perkembangan teknologi yang berfungsi sebagai alat bantu kerja, seperti alat bantu untuk mengelola data, baik data yang berskala besar maupun data berskala kecil. Komputer juga sudah digunakan oleh sistem dunia pendidikan untuk mengelola data akademik, salah satu data akademik yang dikelola adalah mutasi siswa atau perpindahan peserta didik yang digunakan oleh Dinas Pendidikan Provinsi Jawa Barat. Mutasi siswa adalah perpindahan peserta didik dari kelas yang satu ke kelas yang lain, yang sejajar atau perpindahan perserta didik dari sekolah satu ke sekolah yang lain yang sejenis.

Dinas Provinsi Jawa Barat merupakan sebuah perusahaan yang bergerak dibidang pelayanan pendidikan, yang memiliki beberapa bagian salah satunya bidang Pembinaan Sekolah Menengah Atas (PSMA). Setiap perusahaan yang berkembang, kadang kala menemukan berbagai macam permasalahan sehingga perlu diimbangi dengan meningkatkan sistem yang ada. Didalam bidang PSMA sendiri belum menggunakan sebuah sistem informasi pada proses pendaftaran mutasi siswa, dimana ketika pendaftar ingin meminta surat rujukan mutasi, sedangkan surat rujukan mutasi dari Dinas Pendidikan Provinsi Jawa Barat harus ditandatangani oleh kepala bidang, dimana kepala bidang tersebut tidak selalu berada di tempat. Hal ini membuat surat rujukan tidak selalu selesai pada saat itu juga, dan menyebabkan surat rujukan yang di inginkan pendaftar menjadi lama. Adapun kendala lainnya yaitu, pendaftar tidak mengetahui alur prosedur, kemana sajakah pendaftar harusnya melakukan pendaftaran mutasi sebelum melakukan pendaftaran pada Dinas Pendidikan Provinsi Jawa Barat. Masalah lainnya ada pada penyimpanan berkas yang cenderung menumpuk. sehingga disaat akan mencari berkas yang ingin dicari akan sulit untuk ditemukan dan bisa saja berkas tersebut hilang ataupun rusak.

Penelitian yang dilakukan oleh Mukhammad Indra, Deri Julian yang berjudul, "Perancangan Sistem Informasi Pelayanan SK Pensiun dan mutasi di Badan Kepegawaian Negara (BKN) Kantor Regional III Bandung”. Tujuan dari penelitian ini adalah dengan membuat proses penyimpanan data agar tidak tercecer dan bahkan hilang, persamaan peneliti ini dengan penelitian yang dibuat oleh penulis adalah sama-sama membicarakan mutasi, dan data yang masih menumpuk. Untuk perbedaanya penelitian terdahulu ini membahas proses mutasi pegawai dan proses pengesahan SK pensiun, sedangkan penulis hanya membahas mutasi saja. Metode penelitian yang dilakukan studi lapangan, observasi, wawancara. Metode pengembangan sistem yang digunakan adalah prototype [1].

Nadya Indi Rahesti, melakukan penelitian yang berjudul "Sistem Informasi Distribusi Kelas dan Mutasi Siswa Tingkat Sekolah Menengah Pertama". Tujuan dari penelitian ini adalah untuk mengakomodasikan distribusi siswa sampai siswa mendapatkan kelas dengan mengacu pada standar pendistribusian yang berbeda antar sekolah dan pencatatan secara administratif proses mutasi siswa, persamaan penelitian terdahulu dengan penelitian yang penulis buat adalah sama-sama membahas mutasi siswa, dan untuk perbedaannya, penelitian terdahulu membicarakan mutasi siswa SMP, sedangan penulis akan membahas mutasi siswa SMA. Metode yang digunakan yaitu Usability Testing yang diukur dengan metode System Usability Scale (SUS) dan metode pengembangan sistem yaitu menggunakan prototype. Platform yang digunakan oleh peneliti terdahulu menggunakan Code Igniter [2].

Tujuan dibuatnya sistem ini agar pendaftar mengetahui alur-alur pendaftaran mutasi, dibuatnya database untuk memudahkan mencari data pendaftaran siswa SMA dan membuat sistem informasi pendaftaran mutasi siswa sma dengan platform web. Diharapkan dengan dibuatnya Perancangan sistem informasi mutasi siswa SMA. Penulis berikan berdasarkan uraian latar belakang tersebut, dimana sistem informasi ini dapat memudahkan pendaftar agar efektif (Pendaftar tidak perlu 
mengantri atau tidak perlu menunggu lama dalam pengambilan surat rujukan, dan penyimpanan berkas dapat lebih rapih dan aman

\section{METODE/PERANCANGAN PENELITIAN}

\subsection{Kajian Pustaka}

Sistem Informasi Mutasi Siswa adalah Sistem informasi yang melakukan perpindahan siswa atau peserta didik yang dilakukan pada sekolah satu ke sekolah lainnya. Menurut Colin Cherry, pengertian sistem adalah suatu keseluruhan yang telah dibentuk dari berbagai macam bagian atau suatu assambel dari berbagai macam sifat dan bagian-bagian tersebut [3]. Pengertian informasi menurut Abdul Kadir, adalah hasil analisis dan sintesis terhadap data. Dengan kata lain, informasi dapat dikatakan sebagai data yang telah diorganisasikan ke dalam bentuk yang sesuai dengan kebutuhan seseorang [4]. Menurut Leonardi, Sistem informasi dapat di definisikan sebagai kumpulan elemen-elemen yang saling berinteraksi satu sama lain untuk mencapai tujuan tertentu yaitu mengolah data menjadi bentuk yang lebih berarti dan berguna bagi penerimanya serta bermanfaat untuk mengambil keputusan saat ini atau di masa yang akan datang [5].

Mutasi Siswa adalah Perpindahan peserta didik dari kelas yang sejajar atau perpindahan peserta didik dari sekolah satu ke sekolah lain yang sejenis.

Metode pendekatan sistem merupan pendekatan dengan cara bagaimana menggunakan alat alat dan peraturan - peraturan yang melengkapi satu atau lebih tahapan - tahapan pengembangan sistem informasi. Adapun metode pendekatan sistem yang digunakan Penulis adalah dengan metode terstruktur yang memiliki karakteristik berorientasi pada proses dan data, adapun alat-alat yang digunakan dalam metode pendekatan sistem yang digunakan Penulis untuk membangun Perancangan Sistem Informasi mutasi siswa SMA pada Dinas Pendidikan Provinsi Jawa Barat.

Adapun alat-alat yang digunakan dalam metode pendekatan berorientasi terstruktur adalah Flowmap, Data Flow Diagram(DFD), Diagram Konteks, Kamus Data, Normalisasi, Entity relational Diagram(ERD).

Prototyping adalah salah satu pendekatan dalam rekayasa perangkat lunak yang secara langsung mendemonstrasikan bagaimana sebuah perangkat lunak atau komponen-komponen perangkat lunak akan bekerja dalam lingkungannya sebelum tahapan konstruksi aktual.

a. Reusable prototype: Prototype yang akan ditransformasikan menjadi produk final.

b. Throwaway prototype: Prototype yang akan dibuang begitu selesai menjalankan maksudnya.

c. Input/output prototype: Prototype yang terbatas pada antar muka pengguna (user interface).

d. Processing prototype: Prototype yang meliputi perawatan file dasar dan prosesproses transaksi.

e. System prototype: Prototype yang berupa model lengkap dari perangkat lunak.

Tahap-tahap dalam prototyping boleh dikata merupakan tahap-tahap yang dipercepat. Strategi utama dalam prototyping adalah kerjakan yang mudah terlebih dahulu dan sampaikan hasil kepada pengguna sesegera mungkin.

Pengujian Black box merupakan metode perancangan data uji yang didasarkan pada spesifikasi perangkat lunak. Data uji dieksekusi pada perangkat lunak dan kemudian keluaran dari perangkat lunak dicek apakah telah sesuai dengan yang diharapkan 


\subsection{METODE PENELITIAN}

Disini Penulis menggunakan metode penelitian deskriptif. Dimana penelitian desktiptif yaitu bertujuan untuk mengumpulkan informasi mengenai suatu masalah yang ada pada tempat atau lokasi.

Metode pendekatan sistem yang digunakan Penulis, dengan metode terstruktur yang memiliki karakteristik berorientasi pada proses dan data, adapun alat-alat yang digunakan dalam metode pendekatan sistem yang digunakan Penulis untuk membangun Perancangan Sistem Informasi mutasi siswa SMA pada Dinas Pendidikan Provinsi Jawa Barat. Alat-alat yang digunakan dalam metode pendekatan berorientasi terstruktur adalah Flowmap, Data Flow Diagram(DFD), Diagram Konteks, Kamus Data, Normalisasi, Entity relational Diagram(ERD).

Metode pengembangan sistem yang digunakan pada penelitian ini adalah metode pengembangan sistem prototype. Prototyping adalah salah satu pendekatan dalam rekayasa perangkat lunak yang secara langsung mendemonstrasikan bagaimana sebuah perangkat lunak atau komponen-komponen perangkat lunak akan bekerja dalam lingkungannya sebelum tahapan konstruksi aktual dilakukan.

Dalam penelitian ini, pengujian software dilakukan dengan menggunakan pengujian black box/ black box testing. Pengujian Black box adalah pengujian aspek fundamental sistem tanpa memperhatikan struktur logika internal perangkat lunak. Metode ini digunakan untuk mengetahui apakah perangkat lunak berfungsi dengan benar. Pengujian Black box merupakan metode perancangan data uji yang didasarkan pada spesifikasi perangkat lunak.

\section{HASIL DAN PEMBAHASAN}

\subsection{Gambaran Perancangan Sistem}

Perancangan sistem ini adalah dimana proses penyusunan sistem baru dari sistem lama, dimana sistem baru yang dirancang ini diharapkan dapat mengatasi masalah - masalah yang ada di sistem lama.

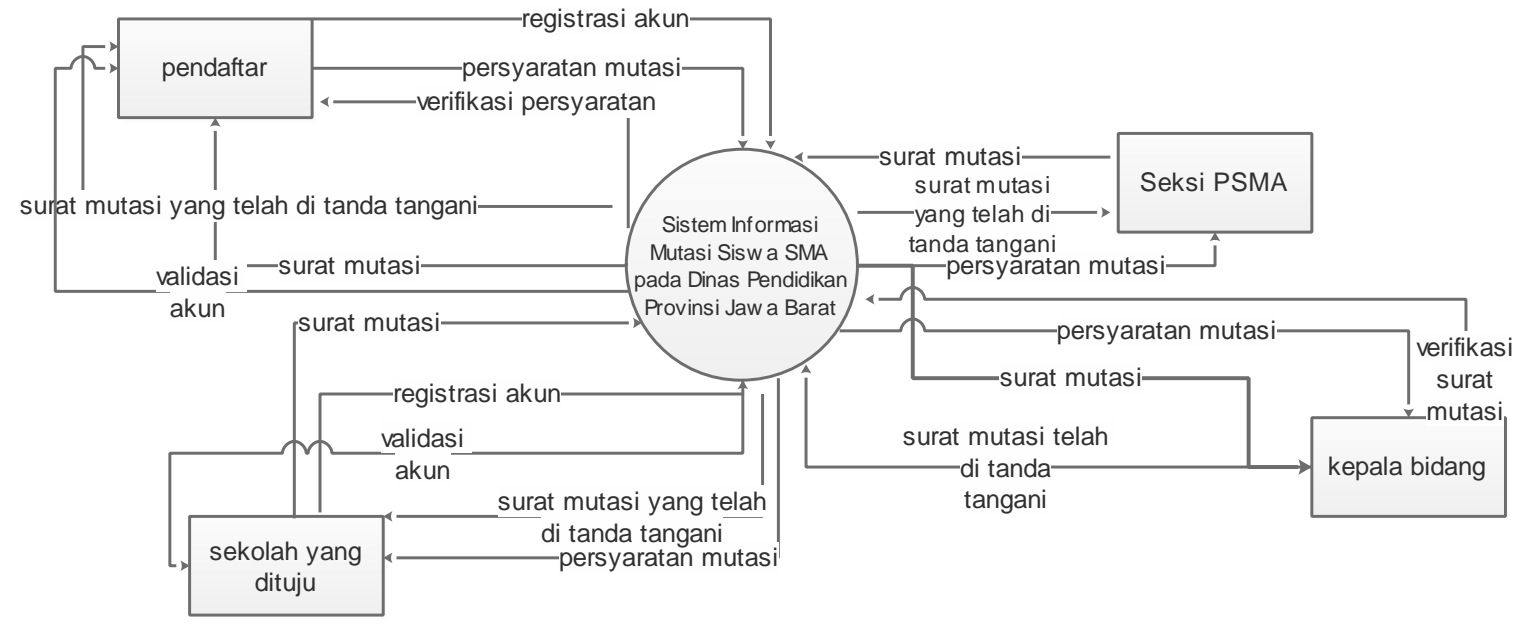

Gambar 1. Diagram Kontek yang diusulkan

\subsection{Implementasi Perangkat Lunak}

Perangkat lunak yang digunakan untuk melakukan implementasi sistem informasi pada Dinas Pendidikan Provinsi Jawa Barat yaitu: 
Tabel 1. Implementasi Perangkat Lunak

\begin{tabular}{|l|l|}
\hline \multicolumn{1}{|c|}{ Perangkat Lunak } & \multicolumn{1}{c|}{ Spesifikasi } \\
\hline Sistem Operasi & Windows 10 Enterprise 64-bit \\
\hline Bahasa Pemrograman & PHP framework Codeigniter \\
\hline Web Server & Apache \\
\hline Database Server & MySQL \\
\hline Web Browser & Mozilla Firefox \\
\hline Core Editor & Sublime Text \\
\hline
\end{tabular}

\subsection{Implementasi Perangkat Keras}

Spesidikasi perangkat keras yang dibutuhkan dalam pengimplementasian sistem informasi pada Dinas Pendidikan Provinsi Jawa Barat yaitu:

Tabel 2. Implementasi Perangkat Keras

\begin{tabular}{|l|l|}
\hline \multicolumn{1}{|c|}{ Perangkat Keras } & \multicolumn{1}{c|}{ Spesifikasi } \\
\hline Processor & Intel(R) Core(TM) i3-3217U CPU @ 1.80GHz \\
\hline RAM & 2 GB \\
\hline VGA & Intel (R) HD Graphics 4000 \\
\hline Harddisk & 100 GB \\
\hline Monitor & Generic Pnp Monitor \\
\hline
\end{tabular}

\subsection{Implementasi Antarmuka}

\section{Implementasi Antarmuka Registrasi}

Implementasi antarmuka Registrasi ini digunakan untuk membuat akun baik untuk pendaftar maupun pihak sekolah yang dituju.

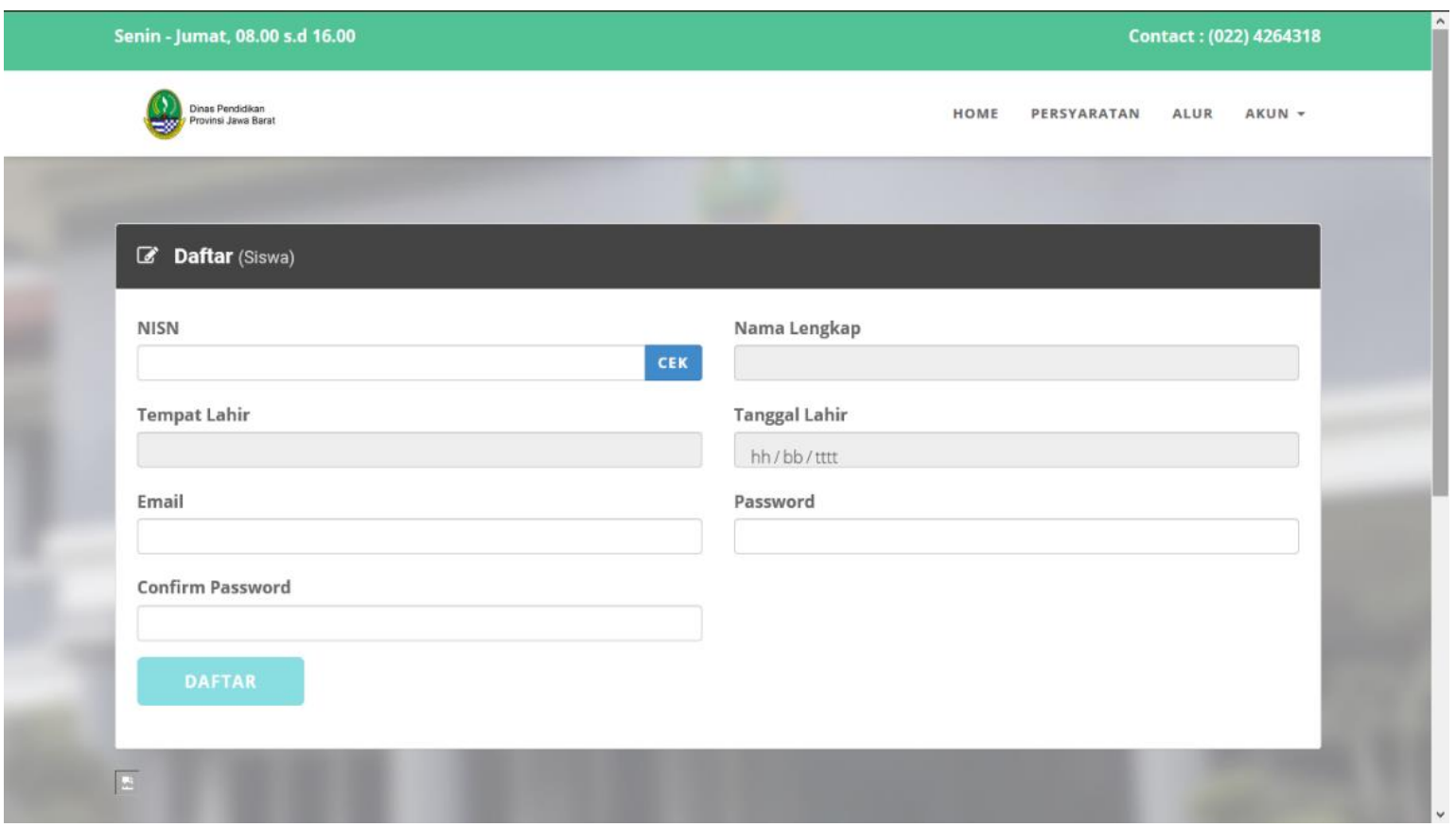

Gambar 2. Implementasi Antarmuka Registrasi untuk Siswa atau Pendaftar 


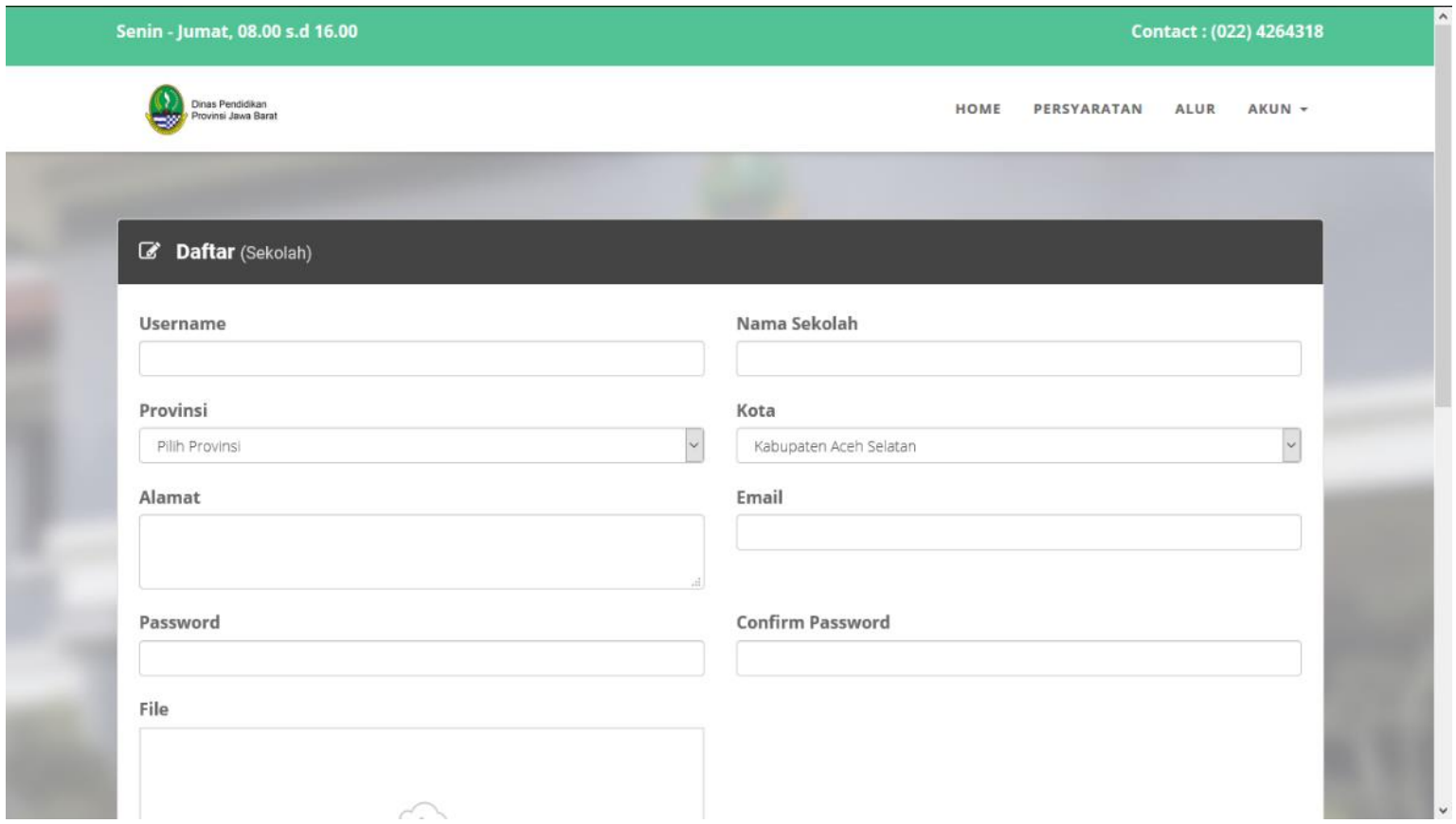

Gambar 3. Implementasi Antarmuka Registrasi untuk Sekolah

\section{Implementasi Antarmuka Login}

Setelah melakukan registrasi atau pembuatan akun, maka akan menampilkan menu login.

\section{Mutasi Siswa}

Dinas Pendidikan

\section{Provinsi Jawa Barat}

Jalan Dr. Radjiman No. 06

Telepon: (022) 4264813, Bandung (40171)

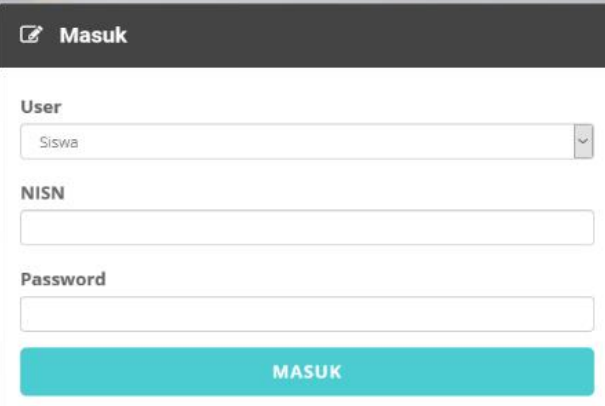

* We'll contact you by phone \& email later

Gambar 4. Implementasi Antarmuka Login 


\section{Implementasi Antarmuka Dashboard Sekolah}

Menu dibawah ini yaitu menu tampilan Dashboard Sekolah, fungsi dashboard sekolah disini yaitu untuk melihat siapa saja yang sudah melakukan pengajuan mutasi ke sekolah tersebut.

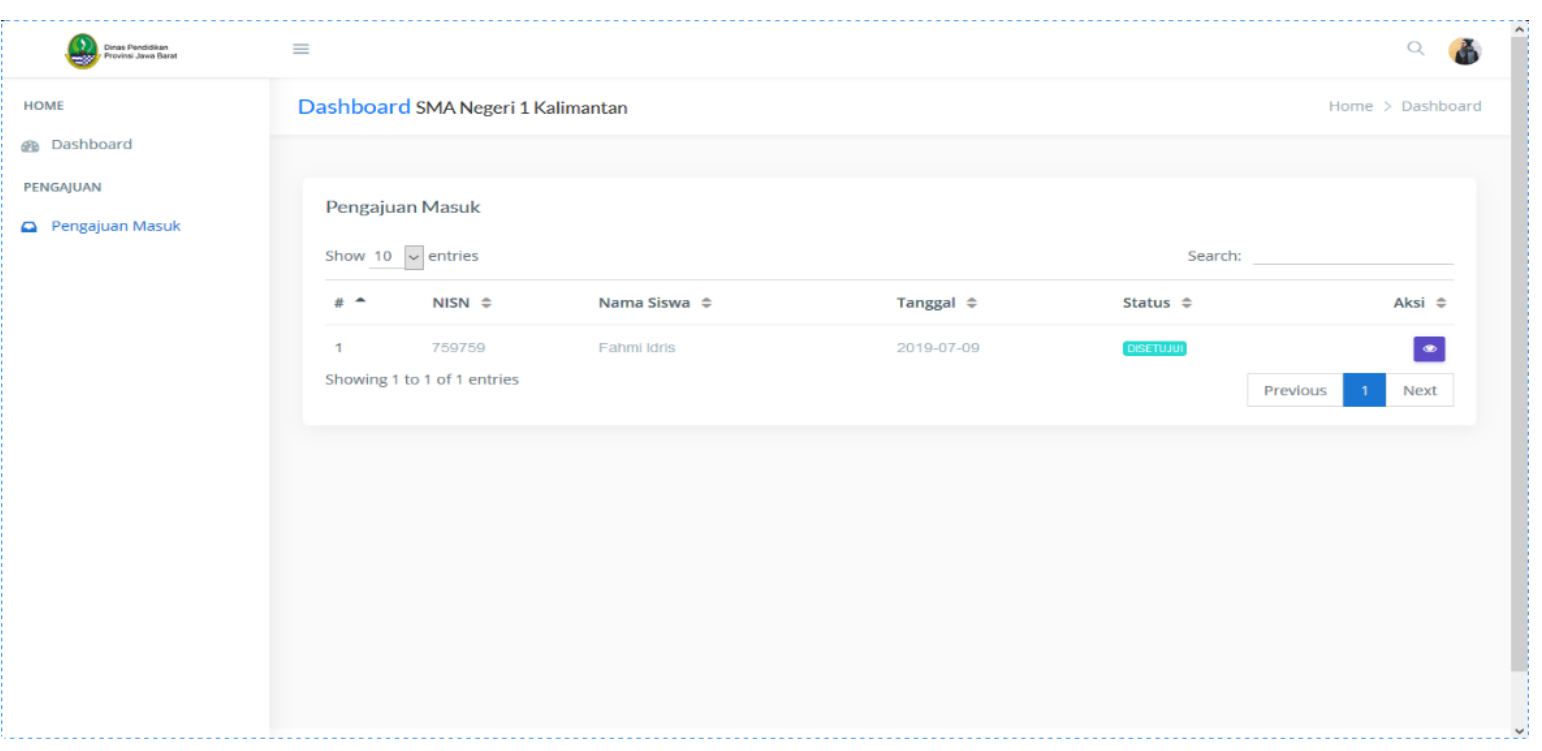

Gambar 5. Implementasi Antarmuka Dashboard Sekolah

\section{Implementasi Antarmuka Login Admin}

Implementasi Antarmuka login yaitu untuk admin.

\begin{tabular}{l} 
Login \\
USERNAME \\
\hline Username \\
PASSWORD \\
\hline PasSword \\
\hline SIGN IN \\
\hline
\end{tabular}

Gambar. 6 Implementasi Antarmuka Login untuk Admin

\section{Implementasi Antarmuka dashboard Admin}

Setelah Admin melakukan login maka akan menampilkan dashboard Admin, di dalam dashboard admin terdapat menu pengajuan masuk, Daftar Sekolah, Data User dan Data Jadwal. 


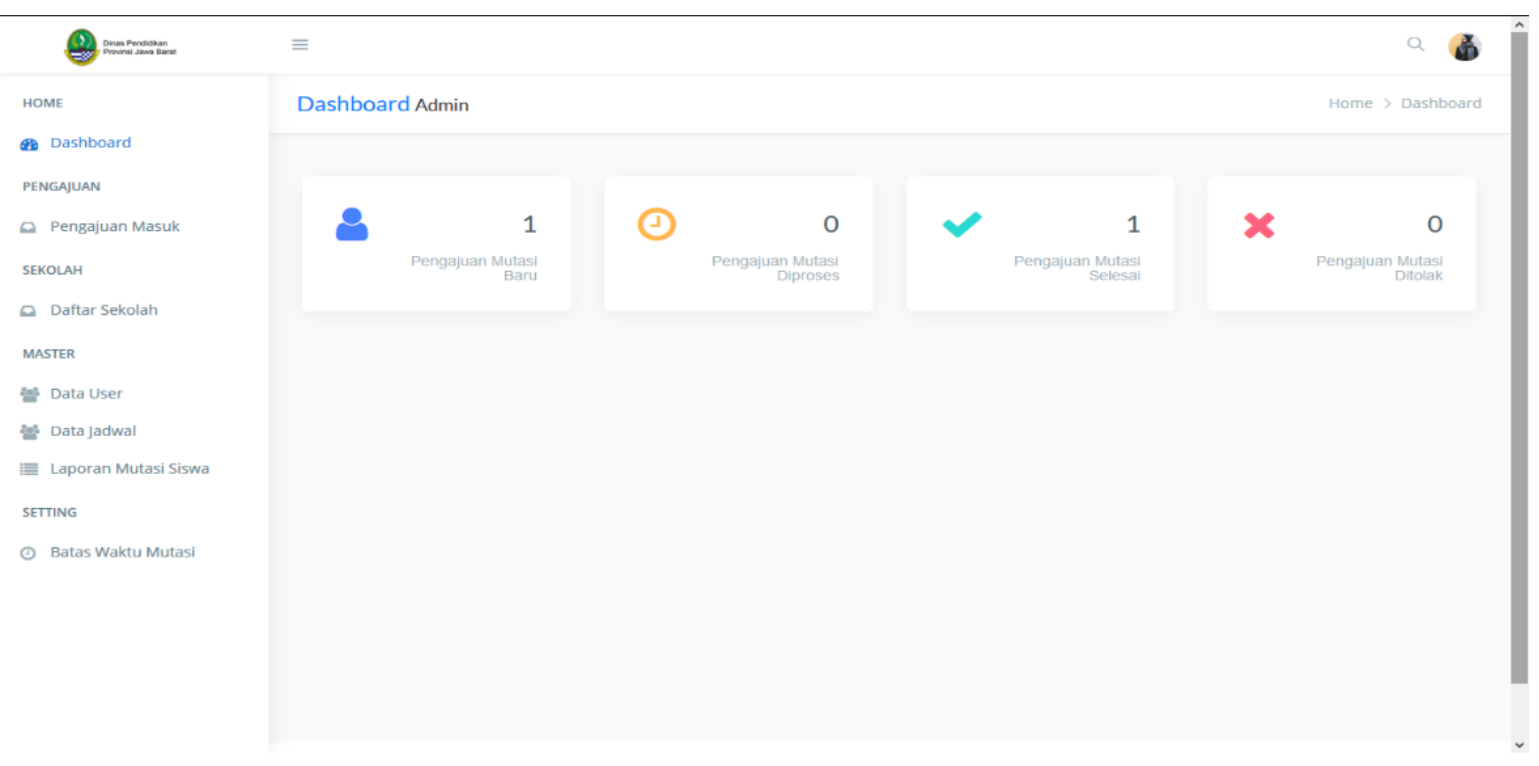

Gambar. 7 Implementasi Antarmuka Dashboard Admin

\section{KESIMPULAN DAN SARAN}

Perancangan Sistem Informasi ini dibuat untuk membantu proses pendaftaran mutasi siswa SMA di lingkungan Dinas Pendidikan Provinsi Jawa Barat, Proses pendaftaran mutasi siswa ini, tidak perlu lagi datang langsung ke Dinas Pendidikan Provinsi Jawa Barat.

Berdasarkan hasil penelitian yang telah dilakukan oleh Penulis, maka Penulis menarik kesimpulan dan mengajukan beberapa saran yang berhubungan dengan pembahasan dalam bab-bab sebelumnya.

1. Untuk memberitahu pendaftar bahwa surat rujukan telah selesai di buat atau di proses.

2. Untuk memberitahukan pendaftar alur - alur apa saja yang harus dilakukan oleh pendaftar.

3. Untuk mempermudah saat melalukan pencarian berkas pendaftar mutasi.

Diharapkan dalam beberapa masa yang akan datang terjadi perkembangan teknologi di dalam lembaga pendidikan. Untuk perancangan sistem informasi mutasi ini masih terbilang sederhana, untuk itu dibutuhkan pengembangan kembali dari segi kelengkapan aplikasi yang dibutuhkan oleh perusahaan.

\section{UCAPAN TERIMAKASIH}

Penulis cukup mengalami beberapa hambatan dan kesulitan. Terbatasnya kemampuan dan wawasan menjadi hambatan besar dalam penyusunan laporan ini. Namun berkat kerja keras dan dukungan dan bantuan dari berbagai pihak seperti dosen Program Studi Sistem Informasi Universitas Komputer Indonesia yang telah memeberikan banyak ilmu dan wawasan yang pada akhirnya Penulis dapat menyelesaikan dengan semaksimal mungkin. Untuk itu dengan segala kerendahan hati, penulis menyampaikan banyak terimakasih yang sebesar-besarnya kepada pihak yang telah membantu Penelitian ini.

\section{DAFTAR PUSTAKA}

[1] Mukhammad Indra, Deri Julian, (2009), "Perancangan Sistem Informasi Pelayanan SK Pensiun dan Mutasi di Badan Kepegawaian Negara (BKN) Kantor Regional III Bandung:, Bandung : 2009 
[2] Nadya Indi Rahesti, "Sistem Informasi Distribusi Kelas dan Mutasi Siswa Tingkat Sekolah Menengah Pertama", Yogyakarta : 2018

[3] COLIN CHERRY, "PENGERTIAN SISTEM: DEFINISI, UNSUR-UNSUR, DAN JENISJENIS SISTEM", 2018 [ONLINE]. TERSEDIA :

HTTPS://WWW.MAXMANROE.COM/VID/MANAJEMEN/PENGERTIANSISTEM.HTML DIAKES TANGGAL 10 APRIL 2019

[4] Abdul Kadir, "Pengenalan Sistem Informasi", Yogyakarta : Andi Offset, 2003

[5] Leonardi Paris Hasugian dan Dimas Ramadhan, "Sistem Informasi Manajemen Bantuan Logistik Bencana Alam Berbasis Web di BPBD Jawa Barat”. Vol. 5, 2017 